\title{
Composite Goodness of Fit in Reaeration Coeffcient Modeling
}

\author{
David O. Omole ${ }^{1}$ \\ ${ }^{1}$ Department of Civil Engineering, College of Science and Technology, Covenant University Canaanland, Ota, \\ Nigeria \\ Correspondence: David O. Omole, Department of Civil Engineering, College of Science and Technology, \\ Covenant University Canaanland, Ota, Nigeria. Tel: 234-803-4006-525. E-mail: \\ david.omole@covenantuniversity.edu.ng
}

Received: June 14, 2012 Accepted: July 19, 2012 Online Published: August 20, 2012

doi:10.5539/enrr.v2n3p71

URL: http://dx.doi.org/10.5539/enrr.v2n3p71

\begin{abstract}
Determination of reaeration coefficient is an important factor in surface water quality modeling as it determines the efficiency of the Streeter-Phelps model used for predicting dissolved oxygen deficit of any stream. This study compared the efficiency of Atuwara model with ten other reaeration coefficients models by making use of three data sets obtained from river Atuwara during the prevalent wet and dry seasons using composite goodness of fit test which was developed by quantitatively combining statistical and graphical goodness of fit. The eleven tested models were ranked in order of performance. Results show that the four top ranking models were developed through a process that utilized data from multiple streams while models that were developed from data obtained from the test subject alone performed less competitively. The outcome of the study also suggests that the usual practice of selecting the best model based on statistical analysis alone does not necessarily yield the best result and therefore recommended the incorporation of quantitatively analyzed graphs. The paper concludes that selection of the best performing model among existing reaeration coefficient models using the composite goodness of fit may present a cheaper and better alternative to conventional model development approach.
\end{abstract}

Keywords: re-aeration coefficient, algorithm, error statistics, fit, Atuwara, modeling, surface water

\section{Introduction}

Computation of reaeration coefficient $\left(k_{2}\right)$ is an integral part of the process of modeling the dissolved oxygen of any surface water body (Chapman, 1996; Lin \& Lee, 2007; Omole, Adewumi, Longe, \& Ogbiye, 2012). Several $k_{2}$ models have been proposed and their distinguishing factor has been their capacity to predict measured data with minimum error. This has been demonstrated through several publications on reaeration coefficient modeling (Streeter, Wright, \& Kehr, 1936; O'Connor \& Dobbins, 1958; Owens, Edwards, \& Gibbs, 1964, Langbein \& Dururn, 1967; Bansal, 1973; Bennet, \& Rathburn, 1972; Long, 1984; Baecheler \& Lazo, 1999; Jha, Ojha, \& Bhatia, 2001; Agunwamba, Maduka, \& Ofosaren, 2007; Longe \& Omole, 2008; Omole \& Longe, 2012) beginning with the pioneering work of Streeter and Phelps (1925) where it was established that dissolved oxygen (DO) content of surface water bodies is used up in breaking down biological and chemical wastes. The quantity of oxygen that would be required to break down these wastes completely was described as biochemical oxygen demand (BOD). Streeter and Phelps (1925) therefore succeeded at providing a mathematical relationship between DO and BOD, thus setting the pace for understanding the process. Subsequent researches proposed different $k_{2}$ models, most of which were validated by presenting the regression statistic and probably by comparing it with one other existing model. Although $k_{2}$ models are characteristically empirical, models such as O’Connor \& Dobbins (1958), Owens, et al. (1964), Langbein \& Dururn, (1967), Bansal, (1973) and, Bennet \& Rathburn, (1972) were developed for application in multiple geographical locations. However, since each surface water body is unique, adopting a single $k_{2}$ model for modeling multiple water bodies must be done carefully following a robust and objective analysis of multiple models. Furthermore, the development of an empirical $k_{2}$ model requires data collection which involves repeated field trips, water sampling, stream geometry measurements, laboratory tests of water samples, and data analysis. This tedious and expensive approach could probably be avoided by use of an alternative approach which involves testing a group of reaeration coefficients models that were previously developed under conditions similar to local conditions. The conventional approach embraces the generation of null hypothesis and the application of statistical analysis of data in drawing inferences because of its quantitative outlook. Error statistics in particular helps to select the model that 
minimizes error. However, the use of graphs visually demonstrates the comparison between measured and simulated data and thus presents an argument that may agree with or differ from statistical inference. A perfect fit of the two plotted lines therefore show that the simulated data perfectly represents the measured data and the equation of the line simulating data becomes the perfect model. Otherwise, the line that best simulates measured data becomes the preferred model. Therefore, the current study, which may be the first of its kind, proposes a method that combines both statistical and visual inspection of graphs of multiple models using the same data sets.

Table 1. Selected models for composite goodness of fit test (test of performance)

\begin{tabular}{|c|c|c|c|c|}
\hline $\mathrm{s} / \mathrm{n}$ & Model & Authors & Background & Country \\
\hline 1 & $k_{2}=46.2679 \frac{U^{1.5463}}{H^{0.0128}}$ & $\begin{array}{l}\text { Atuwara (Omole \& } \\
\text { Longe, 2012) }\end{array}$ & $\begin{array}{l}\text { Based on data gathered from River Atuwara in Southwest Nigeria. Range: }(0.01<\mathrm{U}< \\
1.15 \mathrm{~m} / \mathrm{s}: 0.1<\mathrm{H}<3.56 \mathrm{~m}) \text { where } \mathrm{U} \text { is velocity and } \mathrm{H} \text { is hydraulic radius }\end{array}$ & Nigeria \\
\hline 2 & $k_{2}=12.9 \frac{U^{0.5}}{H^{1.5}}$ & $\begin{array}{c}\text { O’Connor \& } \\
\text { Dobbins (1958) }\end{array}$ & $\begin{array}{l}\text { For moderately deep to deep channels. Range: }(0.305<\mathrm{H}<9.14 \mathrm{~m} ; 0.15<\mathrm{U}<0.49 \\
\left.\qquad \mathrm{m} / \mathrm{s} ; 0.5 \leq \mathrm{k}_{2} \leq 12.2 \mathrm{~d}^{-1}\right)\end{array}$ & USA \\
\hline 3 & $k_{2}=11.632 \frac{U^{1.0954}}{H^{0.0016}}$ & $\begin{array}{l}\text { Agunwamba et al. } \\
\qquad(2007)\end{array}$ & $\begin{array}{l}\text { Based on data gathered from creeks in the south-south part of Nigeria. Where } \mathrm{U} \text { is } \\
\text { velocity and } \mathrm{H} \text { is hydraulic radius }\end{array}$ & Nigeria \\
\hline 4 & $k_{2}=5.792 \frac{U^{0.5}}{H^{0.25}}$ & Jha et al., (2001) & Based on data obtained from River Kali in India & India \\
\hline 5. & $k_{2}=5.026 \frac{U^{0.969}}{H^{1.673}}$ & Streeter \& Phelps & Based on data gathered from River Ohio, USA & USA \\
\hline 6 & $k_{2}=10.046 \frac{U^{2.696}}{H^{3.902}}$ & $\begin{array}{l}\text { Baecheler \& Lazo } \\
\qquad(1999)\end{array}$ & For slight slope rivers in a mountainous environment & Chile \\
\hline 7 & $k_{2}=21.7 \frac{U^{0.67}}{H^{1.5}}$ & Owens et al., (1964) & $\begin{array}{l}\text { Oxygen recovery monitored for six streams in England following de-oxygenation with } \\
\text { sodium sulfite. Range: }(0.12<\mathrm{H}<3.35 \mathrm{~m} ; 0.55<\mathrm{U}<1.52 \mathrm{~m} / \mathrm{s}\end{array}$ & England \\
\hline 8 & $k_{2}=4.67 \frac{U^{0.6}}{H^{1.4}}$ & Bansal (1973) & Based on re-analysis of re-aeration data of numerous data & USA \\
\hline 9 & $k_{2}=20.2 \frac{U^{0.607}}{H^{1.689}}$ & $\begin{array}{l}\text { Bennet \& Rathburn } \\
\qquad(1972)\end{array}$ & Based on re-analysis of historical data & USA \\
\hline 10 & $k_{2}=1.923 \frac{U^{0.273}}{H^{0.584}}$ & Long (1984) & Based on data collected from streams in Texas. Equation also known as Texas equation & USA \\
\hline 11 & $k_{2}=7.6 \frac{U}{H^{1.33}}$ & $\begin{array}{l}\text { Langbein \& Dururn } \\
\qquad(1967)\end{array}$ & $\begin{array}{l}\text { Based on synthesis of data from O'Connor and Dobbins (1958), Churchill et al., } \\
\text { (1962), Krenkel \& Orlob (1963), Streeter et al., (1936) }\end{array}$ & USA \\
\hline
\end{tabular}

The selected models for this study are Atuwara (Omole \& Longe, 2012), Streeter et al. (1936) (which is also known as US Geological Survey equation), O’Connor \& Dobbins (1958), Owens et al. (1964), Langbein and Dururn (1967), Bansal (1973), Bennet and Rathburn (1972), Long (1984), Baecheler and Lazo (1999), Jha et al., (2001) and, Agunwamba et al. (2007) model which was developed in southern Nigeria using data obtained during the wet season only (Table 1). The Streeter et al. (1936) model was selected because it is the first proposed $k_{2}$ model. O'Connor and Dobbins (1958), Owens, et al. (1964), Langbein and Dururn, (1967), Bansal, (1973) and, Bennet and Rathburn, (1972) were selected because each of them simulated multiple rivers which possess diverse characteristics such as stream depth and speed. Long (1984) was selected because Texas state has high temperatures during summer which is similar to the tropics. Baecheler and Lazo (1999) was selected because of its gentle slope which is similar to river Atuwara's. Jha et al. (2001) was selected because the climatic 
conditions in western Uttar Pradesh in India where the model was developed is similar to river Atuwara environ (Yadav et al., 2008). Finally, Agunwamba et al. (2007) was selected because it was developed in Nigeria also.

\section{Materials and Methods}

Three data sets obtained from river Atuwara were used for the analysis. The data sets were obtained in March and July 2009 as well as January 2010. The March and January data represented data taken during the dry season while July data represented data during the peak of wet season when there is high dilution of pollutant load. January was the most critical period because of the dry weather flow which is characterized by low stream velocity and discharge. All effluent discharges into the river body at this time have maximum impact because of the low dilution of pollutant concentration. Detailed discussion on how the data sets were obtained and how Atuwara model was developed are fully discussed in Omole and Longe (2012). Selection of the best model from among existing models for river Atuwara, which is the focus of this study, was based on criteria such as availability in literature, the similarity of model parameters, stream geometry, stream speed, the type of climate from which model was developed, and the robustness of analysis that led to the development of the model. Other model specific factors for choosing the test models are summarized in Table 1.

\subsection{Theoretical Concept}

The efficiency of a model can be defined as its ability to adequately predict observed data with minimal error. The best model is therefore deemed as having the best goodness of fit (Berthouex \& Brown, 2002; Montgomerry \& Runger, 2003; Chatterjee \& Hadi, 2006). Goodness of fit can be categorized into two. These are statistical goodness of fit and graphical goodness of fit (Montgomerry \& Runger, 2003; Omole, 2011). The former is based on an array of statistically determined error parameters such as estimated variance (standard error), sum of squares of regression (SSR); coefficient of determination $\left(\mathrm{R}^{2}\right)$; adjusted coefficient of determination (Adj. $\mathrm{R}^{2}$ ) and root mean square error (RMSE). Furthermore, statistical error parameters such as SE, SSE, SSR, and RMSE whose values are closer to 0 indicate a better fit. Also, models with higher values of statistical parameters such as $\mathrm{R}^{2}$ and Adjusted $\mathrm{R}^{2}$ indicate better fit (Runger \& Montgomery, 2003). The graphical goodness of fit is based on visual inspection which could be a subjective but nonetheless highly useful tool. This is because a model could have minimum error and still be visually non-predictive (Montgomery \& Runger, 2003). In order to compare the predictive capacity of eleven $\mathrm{k}_{2}$ models, the statistical goodness of fit of each model is determined using the procedure described in the flowchart (Figure 1). 


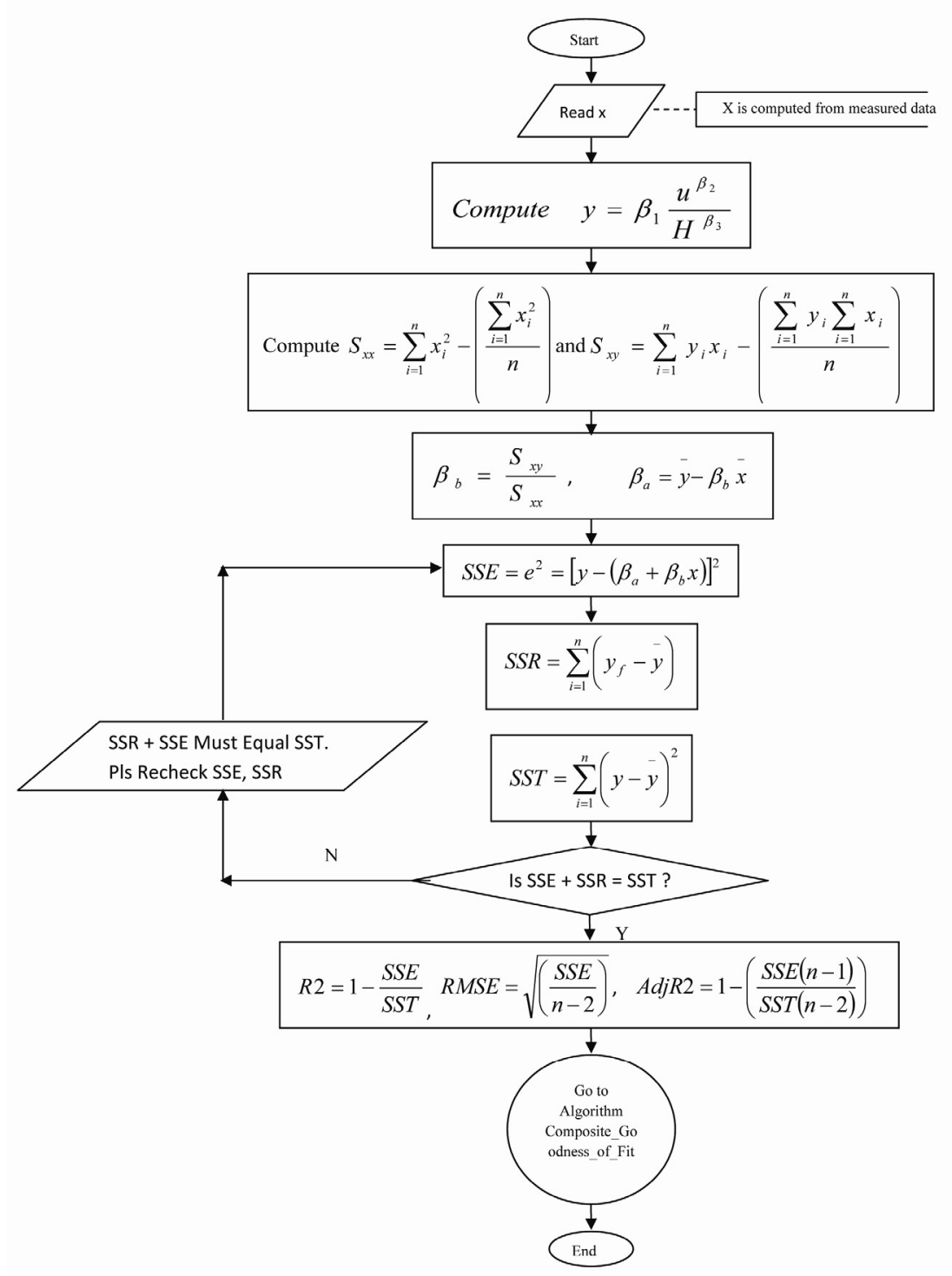

Figure 1. Flowchart showing the progression of the statistical analysis

\subsection{Procedure for the Composite Goodness of Fit}

The statistical values and graphs are the input data for the composite goodness of fit procedure described by the algorithm stated below (Lines 1-3 of data structure). The procedure operates by adapting the Likert scale system of weight allocation (Page-Buchi, 2003; Uebersax, 2006; Longe, Longe, \& Ukpebor, 2009) to statistical and graphical input data (Steps 4, 6, 8, 10,12 and 15). For the statistical input data, the error term for the best model is expected to be the least. Therefore, the model with the minimum error is allocated the highest weight, $n$. Likewise, the best model is expected to have the highest value of coefficient of determination. Therefore, the highest weight is allocated to the model with the highest $\mathrm{R}^{2}$ or Adjusted $\mathrm{R}^{2}$. For the graphical input data, the weights are allocated by inspection. The response trend line that best imitates the measured data trend line is allocated the highest weight. If two models display the same statistical value or trend line, the same values are allocated to them. However, the value of weight that may be allocated to the next model will be $m-j$, where $m$ is the weight value shared by two or more models and $j$ is the number of models that share the value. Another sensitive part of the composite goodness of fit is the allocation of importance to the statistical and graphical components of the composite goodness of fit (Steps 16-22 of the algorithm). For this study, equal importance was given to them therefore each carried a 50\% cumulative weight in the final analysis (Steps 25-26). 


\section{Data Structure}

1. Stat: array of records: Each record has 14 fields

Fields in a record: Type, SSE, SSR, RMSE, R2, SSEW, SSRW, RMSEW, R2W, ADJR2 ADJR2W, SUMOFALL, Wsfactor, Wgfactor

2. Graph: array of records: Each record has 3 fields

Fields in a record: Type, Weight, Wgfactor

3. Merge: array of of records: Each record has 2 fields

Fields in a record: Type, Overallweight

\section{ALGORITHM OF COMPOSITE GOODNESS OF FIT}

STEP 1: $\quad$ Initialize Stat, Graph, Merge

STEP 2: $\quad$ For $\mathrm{i}=1$ to 11

Begin

Stat $[\mathrm{i}]$. Type $=\mathrm{i} ; / /$ model name $1,2,3 \ldots 11$

Compute

Stat[i].SSE;

Stat[i].SSR;

Stat[i].RMSE;

Stat[i].R2;

Stat[i].ADJR2;

End

STEP 3: Sort Stat in ascending order of Stat.SSE

STEP 4: $\quad$ For $\mathrm{i}=1$ to 11

Begin

Assign weight to Stat[i].SSEW;

//highest weight to least value of SSE

End

STEP 5: $\quad$ Sort Stat in ascending order of Stat.SSR

STEP 6: $\quad$ For $\mathrm{i}=1$ to 11

Begin

Assign weight to Stat[i].SSRW;

//highest weight to least value of SSR

End

STEP 7: $\quad$ Sort Stat in ascending order of Stat.RMSE

STEP 8: $\quad$ For $\mathrm{i}=1$ to 11

Begin

Assign weight to Stat[i].RMSEW;

//highest weight to least value of SSE

End

STEP 9: $\quad$ Sort Stat in ascending order of Stat.R2

STEP 10: For $\mathrm{i}=1$ to 11

Begin

Assign weight to Stat[i].R2W;

//highest weight to highest value of R2 
End

STEP 11: Sort Stat in ascending order of Stat.AdjR2

STEP 12: $\quad$ For $\mathrm{i}=1$ to 11

Begin

Assign weight to Stat[i].AdjR2W;

//highest weight to highest value of AdjR2

End

STEP 13: For $\mathrm{i}=1$ to 11

Begin

Stat[i].SUMOFALL=Stat[i].SSEW+Stat[i].SSRW+Stat[i].RMSEW+Stat[i].R2W+Stat[i].AdjR2W;

End

STEP 14: Sort Stat in descending order of Stat.SUMOFALL

//the model in Stat[1].Type is the best model

STEP 15: For $i=1$ to 11

Begin

Graph[i].Type =i; //model name

Print "Enter graphical weight for model \%d: " i;

Input Graph[i].Weight;

End

STEP 16: Print "Enter Graphical Percentage: "

STEP 17: Input N1

STEP 18: Print "Enter Statistical Percentage: "

STEP 19: Input N2

STEP 20: Print "Caution: N1+N2 should be equal to 100 "

STEP 21: $\quad$ gfactor $=\frac{N 1}{100}$

STEP 22: $\quad$ sfactor $=\frac{N 2}{100}$

STEP 23: $\quad$ For $\mathrm{i}=1$ to 11

Begin

Graph $[\mathrm{i}] \cdot$ Wgfactor $=$ gfactor $*$ Graph[i].Weight;

Stat $[\mathrm{i}]$. Wsfactor $=$ sfactor $*$ Stat $[\mathrm{i}]$. SUMOFALL;

End

STEP 24: Sort Stat in ascending order of Stat.Type

STEP 25: $\quad$ For $\mathrm{i}=1$ to 11

Begin

Merge[i].Type $=\mathrm{i} ; \quad / /$ model name

Merge[i]. Overallweight $=$ Stat $[\mathrm{i}]$. Wsfactor + Graph $[\mathrm{i}]$.Wgfactor;

End

STEP 26: $\quad$ Sort Merge in descending order of Merge.Overallweight

//the first i.e. Merge [1].Type is the best overall model having combine Stat \& Graph 


\section{Results and Discussion}

\subsection{Statistical Analysis}

Subsequent to the statistical analysis of data, all the pre-selected models were ranked according to how well they minimized error and maximized fit. Models which performed better were allocated the higher scores (Table 2). The ranking was done for each data set and then combined to find an average score which was then converted to percentages in the last row of Table 2. Results show that each data set presented fluctuations in ranking for most of the models but a few of the models had consistently high scores. The fluctuations were expected considering that the different data represented extreme weather conditions. Regardless, the most representative model is expected to have high rankings in both wet and dry seasons. The combined assessment of the three data sets showed that best ranking model is Long (1984) and this is closely followed by Bansal (1973) model, Streeter et al. 1936, and Agunwamba et al. (2007) in that order. Atuwara model ranked eighth in the cumulative statistical analysis. The unique feature of the two top ranking models is the fact that both were developed using data from multiple streams (Table 1). This further buttress the fact that empirical models developed from particular streams may not necessarily be the most representative model for that stream.

Table 2. Statistical goodness of fit using January, March and July data

\begin{tabular}{|c|c|c|c|c|c|c|c|c|c|c|c|c|c|c|c|c|c|}
\hline & Atuwara w & & O'Connor & & unwambav & w Jha & w Streeter & $\mathrm{w}$ & Baechelerv & w Owens v & w Bansal & w Bennet $v$ & w L & Long $v$ & W I & Langbein & $\mathrm{w}$ \\
\hline \multicolumn{18}{|l|}{ January Data } \\
\hline $\mathrm{SSE}=$ & 129.29 & 8 & 6785.58 & 4 & 16.573 & 1017.99 & $9 \quad 9759.2331$ & & $5 \quad 169141$ & 143299.1 & 12536.633 & 3725186.9 & 93 & 8.432 & 211 & 545.872 & 6 \\
\hline $\mathrm{SSR}=$ & 22.2823 & 8 & 391.431 & 4 & 2.1175 & 91.167 & 71070.90248 & & $\begin{array}{ll}5 & 24793.2\end{array}$ & 13231.22 & 2234.516 & $6 \quad 71714.05$ & & 0.2908 & 11 & 52.1983 & 6 \\
\hline $\mathrm{R} 2=$ & 0.147011 & 11 & 0.05454 & 2 & 0.1133 & 90.061 & 140.085411 & & $7 \quad 0.12784$ & 100.06944 & $4 \quad 60.06043$ & 30.06372 & & 0.0333 & 1 & 0.08728 & 8 \\
\hline $\mathrm{RMSE}=$ & 2.93587 & 8 & 21.269 & 4 & 1.0511 & 101.095 & $\begin{array}{lll}5 & 9 & 7.11446\end{array}$ & & $\begin{array}{ll}5 & 106.189\end{array}$ & 153.7271 & $1 \quad 25.98127$ & $7 \quad 740.9772$ & & 0.7498 & 11 & 6.03253 & 6 \\
\hline Adj. R2= & 0.090141 & 11 & -0.00849 & 2 & 0.0542 & 9 & $\begin{array}{ll}0 & 40.024438\end{array}$ & & 0.0697 & 100.00741 & $16-0.0022$ & $2 \quad 30.0013$ & & 0.0311 & 1 & 0.02643 & 8 \\
\hline TOTAL SCORE & & 46 & & 16 & & 47 & 36 & 29 & 9 & 23 & 18 & 27 & 19 & & 35 & & 34 \\
\hline \multicolumn{18}{|l|}{ March Data } \\
\hline $\mathrm{SSE}=$ & 1201.37 & 5 & 1320.76 & 4 & 91.114 & 928.01 & 110174.5671 & & $7 \quad 3794.77$ & 36178.08 & $\begin{array}{ll}8 & 1129.361\end{array}$ & 84221.66 & 62 & 3.818 & 11 & 229.133 & 6 \\
\hline $\mathrm{SSR}=$ & 27.3381 & 5 & 85.2295 & 4 & 1.2952 & 90.168 & 8116.101995 & & $8 \quad 107.48$ & 3343.823 & $\begin{array}{ll}3 & 16.13083\end{array}$ & 7241.447 & & 0.1718 & 10 & 6.55914 & 6 \\
\hline $\mathrm{R} 2=$ & 0.02225 & 3 & 0.06062 & 11 & 0.014 & 20.006 & $\begin{array}{ll}6 & 10.033774\end{array}$ & & $6 \quad 0.02754$ & . 40.05272 & 290.04525 & 80.0541 & & 0.0431 & 7 & 0.02783 & 5 \\
\hline $\mathrm{RMSE}=$ & 8.94937 & 5 & 9.38354 & 4 & 2.4646 & 91.367 & 7103.411423 & & $7 \quad 15.9055$ & 320.2946 & $\begin{array}{ll}6 & 12.93667\end{array}$ & 816.7763 & & 0.5045 & 511 & 3.90839 & 6 \\
\hline Adj. R2= & -0.04293 & 3 & -0.00201 & 11 & -0.0517 & $2-0.06$ & $\begin{array}{lll}6 & 1-0.03064\end{array}$ & & $\begin{array}{ll}6 & -0.0373\end{array}$ & $4-0.01043$ & $3 \quad 9-0.0184$ & $\begin{array}{ll}8 & -0.009\end{array}$ & & 0.0207 & 7 & -0.037 & 5 \\
\hline TOTAL SCORE & & 21 & & 34 & & 31 & 33 & 34 & 4 & 17 & 21 & 39 & 26 & & 46 & & 28 \\
\hline \multicolumn{18}{|l|}{ July Data } \\
\hline $\mathrm{SSE}=$ & 4843.94 & 1 & 50.254 & 5 & 249.58 & 221.45 & $\begin{array}{ll}5 & 711.21727\end{array}$ & & $9 \quad 20.0913$ & 8151.538 & $\begin{array}{ll}8 & 37.46274\end{array}$ & $4 \quad 10130.324$ & & 0.7124 & $4 \quad 11$ & 32.8521 & 6 \\
\hline $\mathrm{SSR}=$ & 4.05001 & 1 & 0.55222 & 4 & 0.3763 & 50.088 & $\begin{array}{ll}8 & 70.087571\end{array}$ & & $8 \quad 0.00136$ & $11 \quad 1.6657$ & $7 \quad 20.08055$ & $5 \quad 91.45062$ & & 0.0065 & 510 & 0.21255 & 6 \\
\hline $\mathrm{R} 2=$ & 0.00084 & 2 & 0.01087 & & 0.0015 & 30.004 & $4 \quad 40.007746$ & & $66.80 \mathrm{E}-05$ & 10.01087 & 7100.01068 & 80.01101 & 111 & 0.009 & 7 & 0.00643 & 5 \\
\hline RMSE $=$ & 17.9702 & 1 & 1.83037 & 5 & 4.079 & 21.196 & $\begin{array}{ll}6 & 70.864765\end{array}$ & & $9 \quad 1.15733$ & 83.17844 & $4 \quad 30.70535$ & $5 \quad 102.94758$ & & 0.2179 & 11 & 1.47991 & 6 \\
\hline Adj. R2= & -0.06578 & 2 & -0.05507 & & -0.0651 & $3-0.06$ & $\begin{array}{lll}6 & 4 & -0.0584\end{array}$ & & $\begin{array}{ll}6 & -0.0666\end{array}$ & $1-0.05507$ & $710-0.0553$ & $8-0.0549$ & & 0.0571 & 7 & -0.0598 & 5 \\
\hline TOTAL SCORE = & & 7 & & 34 & & 15 & 29 & 38 & 8 & 29 & 28 & 45 & 33 & & 46 & & 28 \\
\hline \multicolumn{18}{|l|}{ AVERAGE SCORE FOR } \\
\hline THREE MONTHS= & & 25 & & 28 & & 31 & 22 & 34 & 4 & 23 & 22 & 37 & 26 & & 42 & & 30 \\
\hline \multicolumn{18}{|l|}{ AVERAGE SCORE FOR } \\
\hline THREE MONTHS $(\%)=$ & & 7.8 & & 8.8 & & 9.7 & 6.9 & 10.6 & & 7.2 & 6.9 & 11.6 & 8.1 & & 13.1 & & 9.4 \\
\hline
\end{tabular}



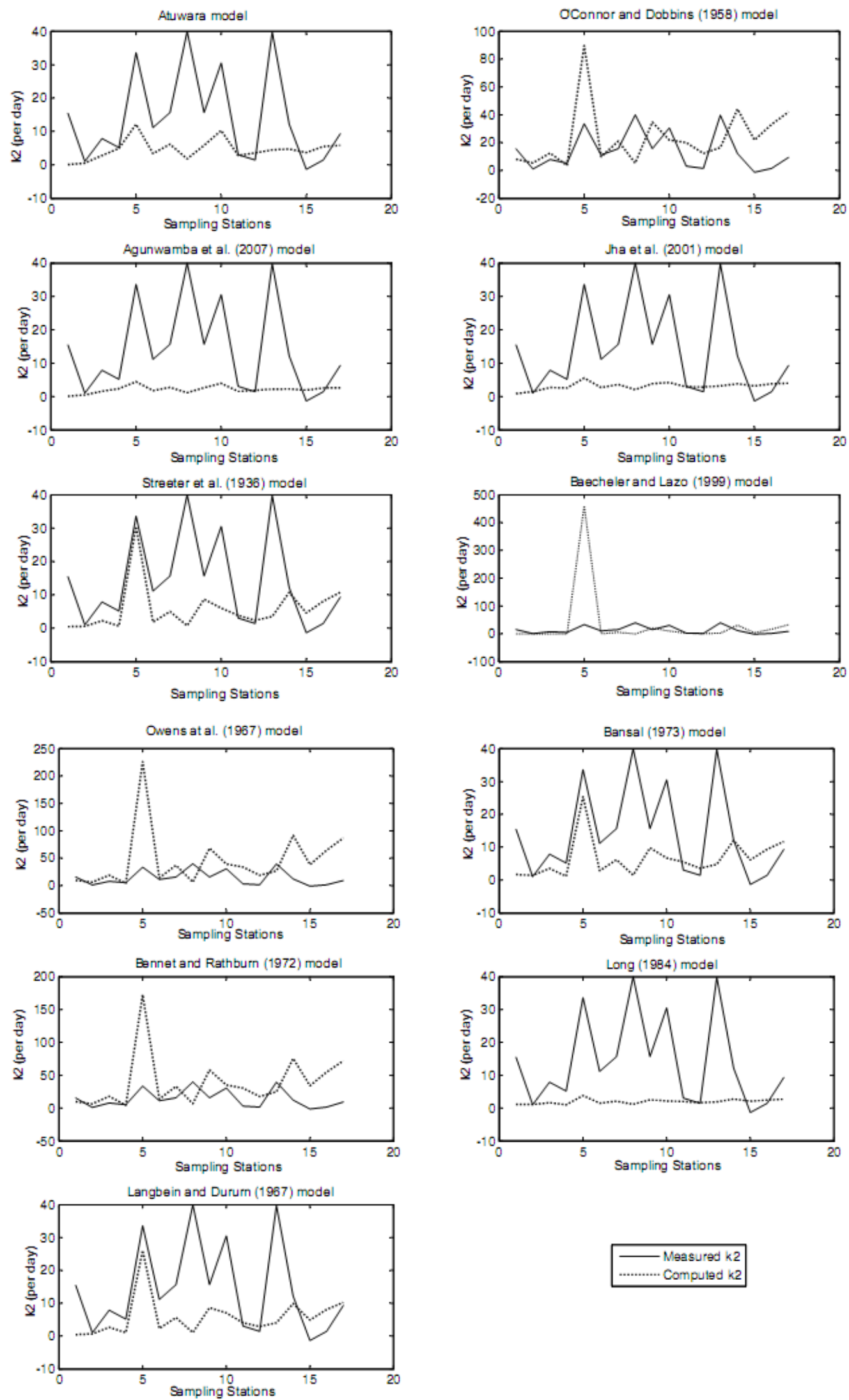

- Measured $k 2$ .......... Computed $k 2$

Figure 2. Plot of individual $k_{2}$ models against measured $k_{2}$ data gathered in January 

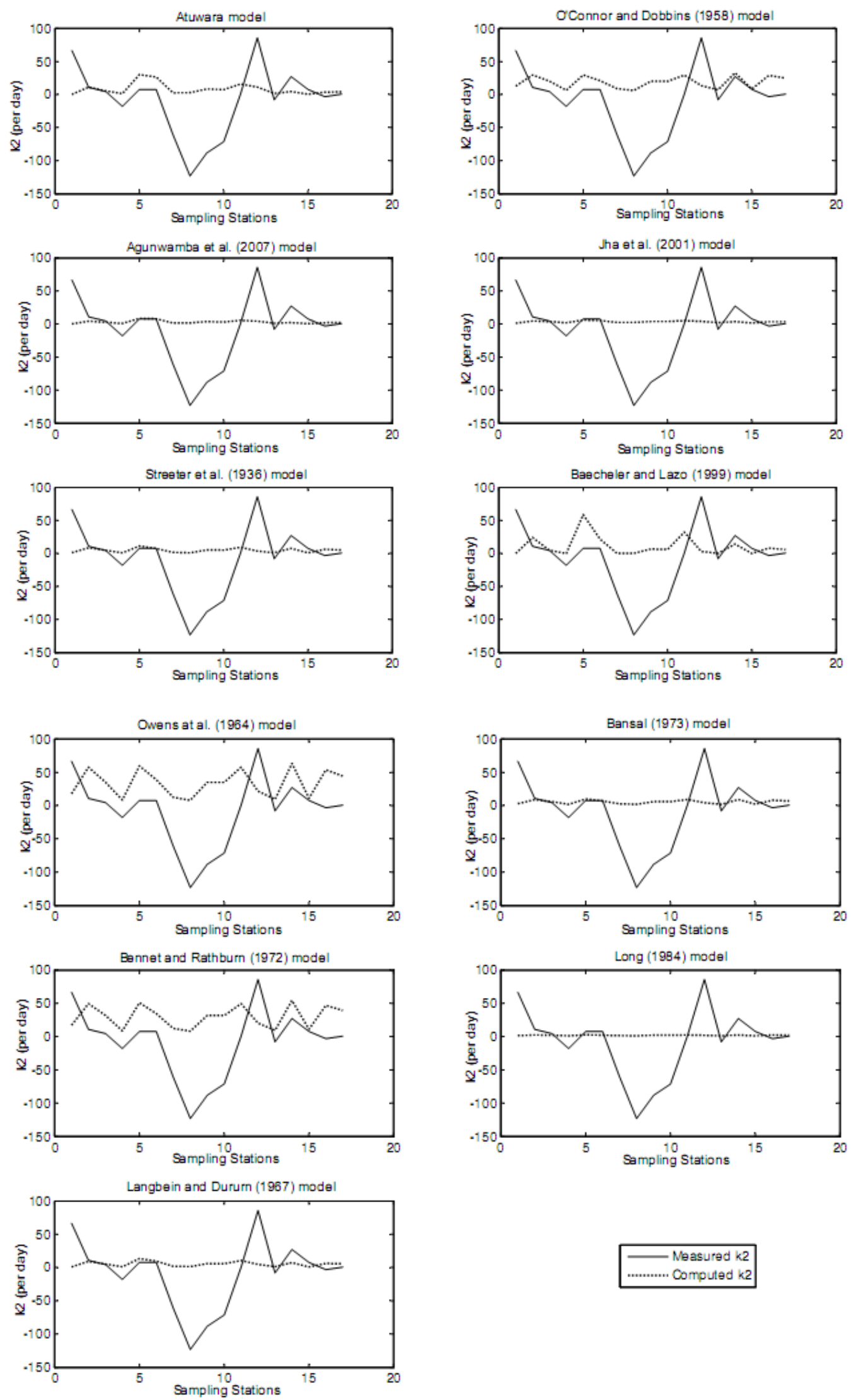

Figure 3. Plot of individual $\mathrm{k}_{2}$ models against measured $\mathrm{k}_{2}$ data gathered in March 

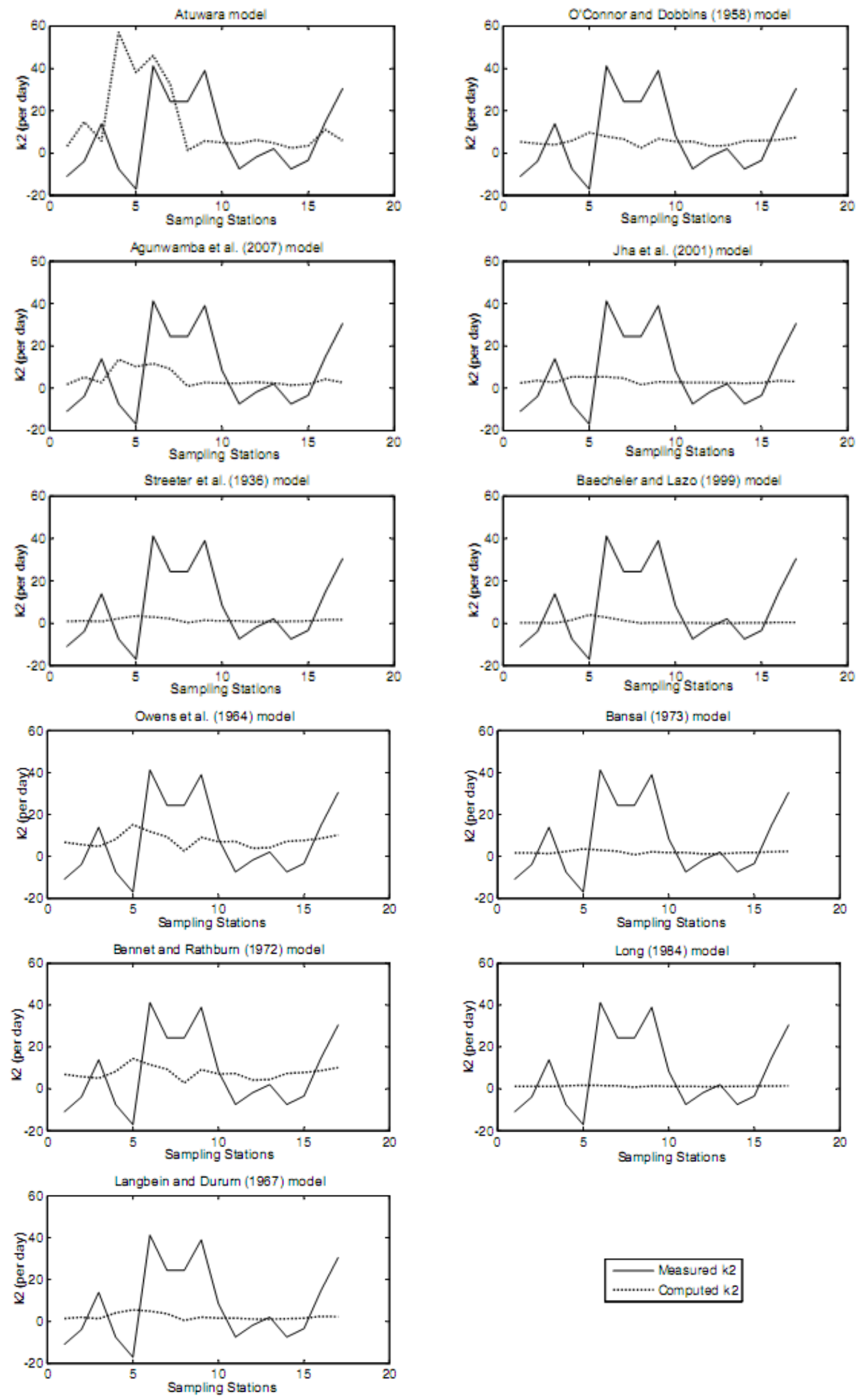

Figure 4. Plot of individual $k_{2}$ models against measured $k_{2}$ data gathered in July 


\subsection{Graphical Inspection and Analysis}

Following the visual inspection of Figures 2-4 which represent the three different data sets, the models were again ranked according to how well the trend lines fit the measured data for each data set by allocating the highest scores to the model with the best fit (Table 3). Worthy of note is that some of the models displayed the same fit within a data set. Such cases attracted the same weight allocation. Like in the statistical analysis, all the scores for the three data sets were combined to produce a ranking for all the models in percentages. The combined values for the three data sets suggest that the models with the best fit were Owens et al. (1964) and Bennet and Rathburn (1972) while O'Connor and Dobbins (1958) model ranked third and Atuwara model ranked fourth (Table 3). Worthy of note is that the four top ranking models in the graphical analysis were completely different from the four top ranking models in the statistical analysis category. This confirms that graphical analysis may not necessarily produce the same results as statistical analysis even though both are very important. It should be noted however that just like in the statistical analysis, the three top ranking models in the graphical analysis were also developed from data gathered from multiple streams (Table 1). This again lends credence to the theory that models developed by using data from single streams may as well be a waste of resources and energy as they may not compete favorably with models developed using multiple data from different streams.

\subsection{Composite Goodness of Fit}

The summary of values from statistical (Table 4, last row) and graphical analyses (Table 3, Row 5) were again combined on an equal percentage basis to give a final model ranking. Results suggest that the model with the least error and best visual representation of data is O'Connor and Dobbins (1958) model (Table 4). The second ranking model following the composite goodness of fit test is Bennet \& Rathburn (1972) and the fifth ranking model is Atuwara. The four top ranking models (Table 4) were all developed using data from multiple locations (Table 1) which again shows that making use of data from multiple streams has a direct positive impact on the model performance. Furthermore, results demonstrated that even though Long (1984) model ranked best following statistical analysis, it did not give a corresponding graphical prediction of measured data (Table 4). In fact, it performed least in graphical analysis as it gave a flat horizontal line in nearly all the graphical plots (Figures 2-4). This therefore suggests that using statistical analysis alone in the selection of reaeration coefficient models or comparing the model with just one or two other models as is common in literature is not the best practice.

Table 4. Order of composite goodness of fit

\begin{tabular}{|c|c|c|c|}
\hline \multirow[t]{2}{*}{$\mathrm{s} / \mathrm{nMODEL}$} & \multicolumn{3}{|c|}{ MODEL RANKING IN ORDERMODEL RANKING IN ORDER } \\
\hline & STATISTICAL ANALYSIS & GRAPHICAL ANALYSIS & \\
\hline 1 O'Connor and Dobbins (1958) model & $6^{\text {th }}$ & $3^{\text {rd }}$ & 11.1 \\
\hline 2 Bennett and Rathburn (1972) model & $7^{\text {th }}$ & $1^{\text {st }}$ & 11.0 \\
\hline 3 Owens et al., (1964) model & $10^{\text {th }}$ & $1^{\mathrm{st}}$ & 10.4 \\
\hline 4 Bansal (1973) model & $2^{\text {nd }}$ & $6^{\text {th }}$ & 9.9 \\
\hline 5 Atuwara model & $8^{\text {th }}$ & $4^{\text {th }}$ & 9.6 \\
\hline 6 Streeter et al., (1936) model & $3^{\text {rd }}$ & $6^{\text {th }}$ & 9.4 \\
\hline 7 Langbein and Dururn (1967) model & $5^{\text {th }}$ & $5^{\text {th }}$ & 9.2 \\
\hline 8 Agunwamba et al., (2007) model & $4^{\text {th }}$ & $6^{\text {th }}$ & 8.9 \\
\hline 9 Long (1984) model & $1^{\mathrm{st}}$ & $11^{\text {th }}$ & 7.5 \\
\hline 10 Jha et al., (2001) model & $10^{\text {th }}$ & $9^{\text {th }}$ & 7.3 \\
\hline 11 Baecheler and Lazo (1999) model & $9^{\text {th }}$ & $10^{\text {th }}$ & 6.0 \\
\hline
\end{tabular}

\section{Conclusion}

The analysis of data collected from River Atuwara in Nigeria using eleven different reaeration coefficient models generated results which suggested that the development of a new reaeration coefficient model for every stream may not necessarily be the best approach in stream DO deficit modeling in terms of cost and model performance 
efficiency. Although Atuwara and Agunwamba et al. (2007) models, which were developed in the Nigerian environment, performed relatively well in the statistical and graphical analyses, O'Connor and Dobbins displayed more remarkable performance which suggests that it could be safely deployed in DO deficit modeling studies on River Atuwara. The selection of a few models out of the several existing models using the composite goodness of fit approach may provide a cheaper and better alternative than the traditional model development approach. Hence, detailed information on the design of existing and future models should be given prominence in scientific publications so as to aid future researchers in short-listing the most suitable models for use in other environments. Furthermore, the study pointed out that the conventional practice of basing scientific inferences on statistical analyses while relegating graphical analyses to complementary status may not yield the most objective inference. Although, graphical analysis is subjective in approach, this study has proposed a way to assess it quantitatively thus making it a very important tool in the selection of models with the best fit.

\section{Acknowledgements}

This research was supported by the International Foundation for Science (IFS), Stockholm, Sweden, through a grant to the author. Mr. A.G. Musa is appreciated for assisting in generating the algorithm while Professor E.O. Longe of the University of Lagos is acknowledged for his scientific advice.

\section{References}

Agunwamba, J. C., Maduka, C. N., \& Ofosaren, A. M. (2007). Analysis of pollution status of Amadi creek and its management. J. of Water Supply: Research and Technology-AQUA, 55(6), 427-435.

Baecheler, J. V., \& Lazo, O. L. (1999). Evaluation of water quality modeling parameters: reaeration coefficient. IAHR, Madrid.

Bansal, M. K. (1973). Atmospheric reaeration in natural streams. Wat. Res. Bull. 11, 491-504. http://dx.doi.org/10.1111/j.1752-1688.1975.tb00702.x

Bennett, J. P., \& Rathburn, R. E. (1972). Reaeration in open channel flow. Professional paper 737. USGS, Reston, VA.

Berthouex, P. M., \& Brown, L. C. (2002). Statistics for environmental engineers. (2nd ed.). Lewis Publishers.

Chapman, D. (1996). Water quality assessments. A guide to the use of biota, sediments and water in environmental monitoring, (2nd ed.). UNESCO/WHO/UNEP, Chapman \& Hall, London.

Chatterjee, S., \& Hadi, A. S. (2006). Regression analysis by example (4th ed.). John Wiley and Sons, New Jersey, USA. http://dx.doi.org/10.1002/0470055464

Jha, R., Ojha, C. S. P., \& Bhatia, K. K. S. (2001). Refinement of predictive reaeration equations for a typical India river. Hydrological Processes, 15(6), 1047-1060. http://dx.doi.org/10.1002/hyp.177

Langbein, W. B., \& Dururn, W. H. (1967). The aeration capacity of streams. Circular S42. U.S. Geological Survey, Reston, VA.

Lin, S. D., \& Lee, C. C. (2007). Water and Wastewater Calculations Manual. McGraw Hill Companies Inc., USA.

Long, E. G. (1984). Letter to Ray Whittmore of Tufts University from Texas department of Water Resources.

Longe, E. O., \& Omole, D. O. (2008). Analysis of Pollution Status of River Illo, Ota, Nigeria. The Environmentalist, 28, 451-457. http://dx.doi.org/10.1007/s10669-008-9166-4

Longe, E. O., Longe, O. O., \& Ukpebor, E. F. (2009). People's perception on household solid waste management in Ojo Local Government Area in Nigeria. Iran Journal of Environmental Health Science and Engineering. 6(3), 209-216.

Montgomerry, D. C., \& Runger, G. C. (2003). Applied statistics and probability for engineers. (3rd ed.). John Wiley and Sons, N.Y.

O'Connor, D. J., \& Dobbins, W. E. (1958). Mechanisms of reaeration of natural streams. ASCE Trans, 153, 641.

Omole, D. O., Adewumi, I. K., Longe, E. O., \& Ogbiye, A. S. (2012). Study of Auto Purification Capacity of River Atuwara in Nigeria. International Journal of Engineering and Technology, 2(2), 229-235.

Omole, D. O., \& Longe, E. O. (2012). Reaeration Coefficient Modeling: A Case Study of River Atuwara in Nigeria. Research Journal of Applied Sciences Engineering and Technology, 4(10), 1237-1243. 
Omole, D. O. (2011), Reaeration Coefficient Modelling: Case study of River Atuwara, Ota, Nigeria. LAP Lambert Academic Publishing GmbH \& Co. KG, Saarbrücken, Germany.

Owens, M., Edwards, R. W., \& Gibbs, J. W. (1964). Some reaeration studies in streams. Int'tl J. Air and Water Pollution, 8, 469-486.

Page-Buchi, H. (2003). The value of Likert scales in measuring attitudes of online learners.

Streeter, H. W., \& Phelps, E. B. (1925), A Study of the Pollution and Natural Purification of the Ohio River. Public Health Bulletin No 146, Public Health Service, Washington DC.

Streeter, H. W., Wright, C. T., \& Kehr, R. W. (1936). Measures of natural oxidation in polluted streams III. Sewage Works J., 8, 282-316.

Uebersax, J. S. (2006). Likert Scales: Dispelling the confusion. Statistical methods for rater agreement.

Yadav, A. S., Gururaja, K. V., Karthik, B., Rao, G. R., Mukri, V., \& Subash, C. M. D. (2008). Ecological status of River Kali flood plain. 